\title{
Realizing the potential of therapeutic stem cells with effective delivery
}

\begin{abstract}
"The investigation of clinical methods for delivering stem cells to the brain and spinal cord is at a much earlier stage of development than delivering stem cells to the heart, reflecting the stage of research into these therapies as a whole."
\end{abstract}

Over the past two decades a wide range of different stem cell types have been investigated for their use in the treatment of diseases with high unmet medical need. A number of treatments for bone regeneration and wound healing based on stem cells have been available for some time. However, the largest areas of research are those looking into treating heart disease, including heart failure, acute myocardial infarction, peripheral vascular disease and stroke, and CNS disorders, including Parkinson's disease, amyotrophic lateral sclerosis and spinal cord injury. Other areas of interest include the treatment of eye diseases, Type 1 diabetes and Crohn's disease.

Strategies under investigation for creating these new stem cell-based therapies use both adult stem cells and embryonic stem cells. The former are readily available from bone marrow, adipose tissue, placenta and umbilical cord blood, are immunocompatible, have been shown to differentiate along multiple cell lineage pathways and are free from the ethical issues associated with embryonic stem cells. More than $80 \%$ of the therapies currently in the research or preclinical stages of development use adult stem cells [1]. Nevertheless, a small number of companies are focusing their efforts on creating novel therapeutics from embryonic stem cells owing to the efficiency with which various cell populations, such as cardiomyocytes, can be created. The first therapy originating from an embryonic stem cell source, Geron's treatment for spinal cord injury, may enter clinical trials in 2010 [101].

The 2007 discovery that pluripotent cells could be created from a genetically reprogrammed human adult skin cell $[2,3]$ has been a true driver for stem cell research. Induced pluripotent stem cells offer the versatility of the embryonic stem cell without the associated ethical issues and the availability of the adult stem cell. These key factors have raised the level of interest in stem cell research among those companies and investors that may have held back in view of political and ethical pressures. Academic researchers across the globe are now working to change the method used for creating induced pluripotent stem cells to make them safe for therapeutic use.

Clinical trials using stem cells to treat cardiovascular diseases provide a clear picture of the current status and challenges to development of stem cell-based therapies. For more than a decade, researchers have attempted to ameliorate heart diseases with adult stem cells taken from a patient's own muscle or bone marrow. Animal studies in this area have shown some promising indications of efficacy [4]. However, clinical trials have shown inconsistent success in translating these improvements into clinically meaningful outcomes for patients with cardiac disease $[5,6]$. Since the publication of these initial clinical findings there has been an increased focus on delivering viable, functioning cells that remain at the desired location, as discussed in detail in the remainder of this article.

\section{Delivering stem cells}

Most therapies under investigation to treat cardiac and CNS diseases will be delivered directly to the damaged area of the target organ (i.e., heart, brain or spinal cord). A small number of stem cell-based therapies are intended for intravenous delivery, but these are mostly based on different mesenchymal stem cell populations that are likely to affect immunomodulatory pathways. Examples include Osiris Therapeutics' Prochymal ${ }^{\mathrm{TM}}$, Angioblast's Revascor ${ }^{\mathrm{TM}}$ and Cellerix’s Ontaril ${ }^{\circledR}$.

Delivering a viable, functioning cell population to a defined location is challenging for several reasons. First, cells may die following injection owing to the sheer forces within an injection catheter [7] or are attacked by the host's immune system. Other factors that have clearly been identified as causes of cell death include inflammation

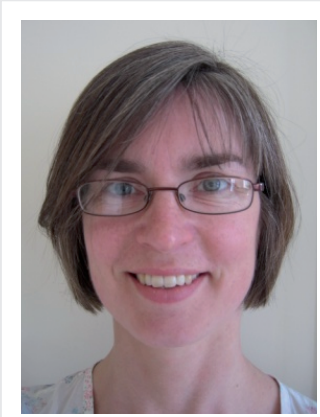

Sara H Sleigh

Author for correspondence: PharmaVision, Nurses Cottage,

Post Office Lane, North Mundham, Chichester, West Sussex, PO20 IJY, UK

Tel.: +44 II5 8469138 Fax: +44 1243785496

E-mail: sara.sleigh@

btopenworld.com

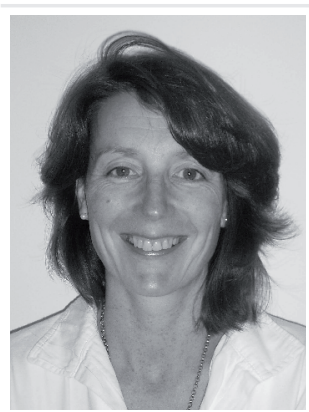

Cheryl L Barton

PharmaVision, Nurses Cottage, Post Office Lane, North Mundham, Chichester, West Sussex, PO2O IJY, UK 
following needle damage to the tissue, and removal of the cells from their extracellular matrix leading to ischemia and apoptosis [8]. Second, communication between cells that is vital for their correct function may be lost. Last, cells delivered by injection often migrate rapidly away from the site of injection: as many as $90 \%$ of injected cells can be lost in this way [9]. These issues are now being addressed through novel materials or methods of delivery with the hope of improving the therapeutic efficacy of the stem cells.

\section{Tissue scaffolds}

The role of tissue scaffolds in the stem cell-based therapy field is becoming increasingly important as researchers aim to address the key issues identified earlier. In the current context, the addition of a scaffold based on a natural or a synthetic material aims to create an optimized environment around cells; this is sometimes referred to as a 'regenerative niche'. The scaffold should provide cell attachment sites that help control the location of the injected cells at densities appropriate for cell growth, correct function, differentiation and proliferation. It helps protect the cells during injection and from the host's immune system. In addition, in some cases, scaffolds can be engineered to include growth factors and/or small molecules that promote cell survival, including alleviating ischemia and tissue regeneration. Over time, the scaffold should degrade leaving functional tissue in its place. The creation of whole new organs using stem cells is a separate area of research that shows immense promise.

\section{"More than $80 \%$ of the therapies currently in the research or preclinical stages of development use adult stem cells..."}

Issues for consideration in scaffold design include: injectability, the porosity of the scaffold (will adequate diffusion of nutrients to the center as well as infiltration of cells from the surrounding tissue be possible?) and its mechanical properties (will these match or interfere with the tissue in question, or create tissue with different properties to the original?).

Scaffolds based on natural and synthetic materials have recently been investigated in animal models of cardiac or CNS disease. In each case, promising results have been reported on various end points in initial animal studies. Natural materials that have been used as scaffolds for delivering drugs as well as cells include fibrin, collagen, alginate and hyaluron. These materials require extensive purification before use and homogeneity issues can hamper their manufacture. Furthermore, some natural materials cause an allergic reaction (e.g., chitosan in people with shellfish allergy) or an immune response (e.g., collagen from animal sources or fibrin from blood products [10]).

Synthetic materials under investigation include polymers based on poly-L-actic-co-glycolic acid (PLGA), poly-L-lactic acid, polyethylene glycol and polyurethane. These materials have a known composition and lend themselves to modification of mechanical properties, porosity and the addition of cofactors. However, low $\mathrm{pH}$ degradation products and immune responses may cause problems with some of these scaffolds [11].

\section{"Clinical trials using stem cells to treat cardiovascular diseases provide a clear picture of the current status and challenges to development of stem cell-based therapies."}

The availability of injectable scaffolds may be of particular relevance in the cardiovascular field and examples of scaffolds that have been tested for the delivery of stem cells in initial animal models include:

- A myoblast-seeded collagen sponge (Gelfoam ${ }^{\circledR}$; Pfizer) that is laid over the infarcted area of the heart during open heart surgery. Rats treated with the Gelfoam construct had better graft functionality after 1 month compared with controls treated with cells in suspension or a bilayer myoblast cell sheet prepared from a fibrin-coated culture plate [12] The noninjectable nature of this scaffold will limit its potential use in the clinic;

- Injectable fibrin scaffolds with bone marrowderived mesenchymal stem cells for cardiac repair. The cells were either injected with fibrin [13] or with fibrinogen/thrombin that polymerized in situ [14]. The former study showed an increase in neovascularization with the use of the scaffold and the latter improvements in cell retention and survival following injection;

- Chitosan tubes seeded with neural cell and progenitor cells [15]. In a complete transection model of spinal cord injury the scaffold showed survival and differentiation of the stem cells. Furthermore, host neurons were identified in the regenerated tissue bridge that formed between the transected cord stumps; 
- Injectable scaffolds based on plasma polymerized allylamine-treated PLGA, which polymerizes in situ in response to the change in temperature upon injection (RegenTec Ltd). In a mouse model, neural stem cells were delivered to stroke-induced cavities in the brain and cells were shown to survive the procedure [16]. Alternative thermoresponsive polymers are also being studied for use in cardiovascular applications but have yet to be tested in vivo [17];

- A new generation of materials - synthetic biological materials - may also be used as tissue scaffolds. These self-assembling peptide nanofibers are formed through the assembly of ionic self-complementary peptides designed by using alternating positively and negatively charged L-amino acids that form highly hydrated scaffolds in the presence of physiological concentration salts [11]. This type of scaffold is very different from the others mentioned, in that it is held together with van der Waals forces and charge rather than covalent bonds, and forms a dynamic medium. Initial studies in which the PC12 cells, Schwann cells or neural precursor cells were injected into the brain or spinal cord showed that proliferation, differentiation and maturation of the cells could be delayed. In addition, immunosuppressants were not required when using young cells.

\section{Delivery methods that \\ address ischemia}

Ischemia resulting from poor vasculature within the target area, or deprivation of cells of their own vascular supply, have been identified as key causes of cell death following transplantation to the heart [8]. Various attempts have been made to address this aspect of stem cell delivery including the use of genetically modified stem cells that encode colony-stimulating factor-1 [18], VEGF [19] or stromal-derived factor-1 [20]. Alternative methods investigated used slowrelease angiogenic factors concomitantly with myoblasts [21] and co-administration of myoblasts with hypoxia-inducible factor-1 [22]. Some approaches shown to be ineffective in increasing cell engraftment include the addition of erythropoietin [23], and cold or heat shock treatment of the cells [24]. Using a different approach, CellMed (a division of Biocompatibles) is developing CellBeads ${ }^{\circledR}$, which contain encapsulated mesenchymal stromal cells engineered to produce glucagon-like peptide-1. CellBeads are currently being tested in patients with hemorrhagic stroke [25].

Similar efforts are being made to overcome inflammatory responses to stem cell injection using mesenchymal stem cells modified to produce IL-18-binding protein [26]. Research in this area has yet to identify the most clinically relevant genetic modification.

\section{Other methods for improving cell retention}

In addition to the use of tissue scaffolds, a variety of alternative approaches to address the problem of cell retention at the desired location are also being taken. One such potential method uses highly focused ultrasound-mediated stimulation of microbubbles filled with gas to pretreat localized areas of tissue. In initial studies in rats, pretreating cardiac tissue increased the transendothelial migration and engraftment of mesenchymal stem cells [27]. A very different approach focuses on ways in which stem cells gravitate towards sites of injury or ischemia. Ryzhov et al. have investigated the use of adenosine to pretreat the cardiac tissue [28]. This increases the adhesion of endothelial progenitor cells to the vascular wall in experimental in vitro models and could potentially be used to increase cell retention locally, although alternative pharmacological pathways may have to be used in place of adenosine [29].

"The creation of whole new organs using stem
cells is a separate area of research that shows
immense promise."

\section{Methods of stem cell delivery in} cardiovascular disease

In early attempts to use stem cells to treat heart diseases, the cells were delivered by intracoronary injection during open heart surgery for reasons such as coronary artery bypass graft. However, more recently researchers have looked to the less invasive method of transendocardial injection and this is now the method of choice for several reasons, including an association with lower morbidity and mortality as well as the ability to apply it to higher risk patients and to repeat the procedure. Recent animal studies have also demonstrated improved cell retention in the heart following catheter-based injection [30].

Most of the ongoing clinical studies using stem cells to treat heart disease are using the $\mathrm{NOGA}^{\circledR}$ electromechanical cardiac mapping 
system (Biosense Webster, a Johnson \& Johnson company). Recent improvements in this system that introduce the possibility of steering a magnetic catheter using an external magnetic field (Biosense Webster/Stereotaxis) offer improvements in fine catheter movement, the ability to reach difficult locations and patient comfort. Further refinements may be made in the future with the use of gadonanotubes to steer and track stem cells (Texas Heart Institute). Catheters that aim to address the key issues surrounding stem cell delivery - retention, survival and location control - are also in development (e.g., MyoCath ${ }^{\mathrm{TM}}$ II from Bioheart Inc. and the C-Cath ${ }^{\mathrm{TM}}$ from Cardio3 BioSciences). Other cardiac imaging modalities, with and without contrast agents, are in use to track the fate of stem cell-based therapies in the heart [31].

\section{Methods of stem cell delivery for diseases}

The investigation of clinical methods for delivering stem cells to the brain and spinal cord is at a much earlier stage of development than delivering stem cells to the heart, reflecting the stage of research into these therapies as a whole. To date, delivery to the brain has been achieved by stereotactic injection, which is an invasive procedure likely to be replaced, especially if results from the first round of clinical trials in this area are positive.

Delivery of cells to the spinal cord is similarly invasive at present, with injections requiring laminectomy to expose the spinal cord [10]. Alternative methods that are less invasive and deliver cells away from the harsh environment at the injury site have been studied, including intrathecal injection [32] and lumbar puncture [33]. Additional devices are in development including a targeted spinal cord injection system [34] and a spinal multisegmental cell and drug delivery system that allow for a reduced number of injections compared with other systems [201]. Clearly, as more stem cell-based therapies for CNS diseases move into the clinic in the coming years additional work will be undertaken in this area.

\section{Conclusion}

The majority of stem cell research in the cardiovascular and CNS areas, the two most active therapeutic areas for stem cell research, has not focused in great detail on the method of cell delivery to date. However, in recent years, there has been a growing realization that the clinical effectiveness of stem cell-based therapies may be limited owing to issues including the delivery of viable, functioning cells that remain at the desired location. Companies and academic laboratories must consider these aspects up front in order to improve the likelihood of their success, rather than making improvements to cell delivery as a secondary factor once efficacy has been established. This will place delivery technologies at the heart of this exciting and growing area.

\section{Financial \& competing interests disclosure}

The authors have no relevant affiliations or financial involvement with any organization or entity with a financial interest in or financial conflict with the subject matter or materials discussed in the manuscript. This includes employment, consultancies, honoraria, stock ownership or options, expert testimony, grants or patents received or pending, or royalties.

No writing assistance was utilized in the production of this manuscript.

\section{Bibliography}

1 Sleigh SH, Barton CL. Stem Cell-Based Therapeutic Delivery: Challenges and Opportunities. PharmaVision, UK (2008).

2 Takahashi K, Tanabe K, Ohnuki M et al. Induction of pluripotent stem cells from adult human fibroblasts by defined factors. Cell 131(5), 861-872 (2007)

3 Yu J, Vodyanik MA, Smuga-Otto K et al. Induced pluripotent stem cell lines derived from human somatic cells. Science 318(5858), 1917-1920 (2007).

4 Boudoulas KD, Hatzopoulos AK. Cardiac repair and regeneration: the Rubik's cube of cell therapy for heart disease. Dis. Model Mech. 2(7-8), 344-358 (2009).
5 Farahmand P, Lai TY, Weisel RD et al. Skeletal myoblasts preserve remote matrix architecture and global function when implanted early or late after coronary ligation into infarcted or remote myocardium. Circulation 118(Suppl. 14), S130-S137 (2008).

6 Abdel-Latif A, Bolli R, Tleyjeh IM et al. Adult bone marrow-derived cells for cardiac repair: a systematic review and meta-analysis. Arch. Intern. Med. 167, 989-997 (2007).

7 Agashi K, Chau DY, Shakesheff KM. The effect of delivery via narrow-bore needles on mesenchymal cells. Regen. Med. 4(1), 49-64 (2009).

8 Menasché P. Towards the second generation of skeletal myoblasts? Cardiovasc. Res. 79(3), 355-356 (2008).
9 Teng CJ, Luo J, Chiu RC, Shum-Tim D. Massive mechanical loss of microspheres with direct intramyocardial injection in the beating heart: implications for cellular cardiomyoplasty. J. Thorac. Cardiovasc. Surg. 132, 628-632 (2006).

10 Willerth SM, Sakiyama-Elbert SE. Cell therapy for spinal cord regeneration. Adv. Drug Deliv. Rev. 60(2), 263-276 (2008).

11 Ellis-Behnke RG, Liang YX, Guo J et al. Forever young: how to control the elongation, differentiation, and proliferation of cells using nanotechnology. Cell Transplant. 18(9), 1047-1058 (2009).

12 Hamdi H, Furuta A, Bellamy V et al. Cell delivery: intramyocardial injections or epicardial deposition? A head-to-head comparison. Ann. Thorac. Surg. 87(4), 1196-1203 (2009). 
13 Huang NF, Lam A, Fang Q et al. Bone marrow-derived mesenchymal stem cells in fibrin augment angiogenesis in the chronically infarcted myocardium. Regen. Med. 4(4), 527-538 (2009).

14 Martens TP, Godier AF, Parks JJ et al. Percutaneous cell delivery into the heart using hydrogels polymerizing in situ. Cell Transplant. 18(3), 297-304 (2009).

15 Zahir T, Nomura H, Guo XD et al. Bioengineering neural stem/progenitor cell-coated tubes for spinal cord injury repair. Cell Transplant. 17(3), 245-254 (2008).

16 Bible E, Chau DY, Alexander MR, Price J, Shakesheff KM, Modo M. The support of neural stem cells transplanted into strokeinduced brain cavities by PLGA particles. Biomaterials. 30(16), 2985-2994 (2009).

17 Wang F, Li Z, Khan M et al. Injectable, rapid gelling and highly flexible hydrogel composites as growth factor and cell carriers. Acta Biomater. 6(6), 1978-1991 (2001).

18 Aharinejad S, Abraham D, Paulus P et al. Colony-stimulating factor-1 transfection of myoblasts improves the repair of failing myocardium following autologous myoblast transplantation. Cardiovasc. Res. 79(3), 395-404 (2008).

19 Yau TM, Kim C, Li G, Zhang Y, Weisel RD, Li RK. Maximizing ventricular function with multimodal cell-based gene therapy. Circulation 112(9), I123-I128 (2005).

20 Elmadbouh I, Haider HKh, Jiang S et al. Ex vivo delivered stromal cell-derived factor- $1 \alpha$ promotes stem cell homing and induces angiomyogenesis in the infarcted myocardium. J. Mol. Cell. Cardiol. 42(4), 792-803 (2007).

21 Sakakibara Y, Nishimura K, Tambara K et al. Prevascularization with gelatin microspheres containing basic fibroblast growth factor enhances the benefits of cardiomyocyte transplantation. J. Thorac. Cardiovasc. Surg. 124(1), 50-56 (2002).

22 Azarnoush K, Maurel A, Sebbah L et al. Enhancement of the functional benefits of skeletal myoblast transplantation by means of coadministration of hypoxia-inducible

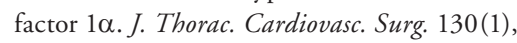
173-179 (2005).

23 Chanséaume S, Azarnoush K, Maurel A et al. Can erythropoietin improve skeletal myoblast engraftment in infarcted myocardium? Interact. Cardiovasc. Thorac. Surg. 6(3), 293-297 (2007).

24 Maurel A, Azarnoush K, Sabbah L et al. Can cold or heat shock improve skeletal myoblast engraftment in infarcted myocardium? Transplantation 80(5), 660-665 (2005).

25 Heile AMB, Wallrapp C, Klinge PM et al. Cerebral transplantation of encapsulated mesenchymal stem cells improves cellular pathology after experimental traumatic brain injury. Neurosci. Lett. 463(3), 176-181 (2009).

26 Wang M, Tan J, Wang Y, Meldrum KK, Dinarello CA, Meldrum DR. IL-18 binding protein-expressing mesenchymal stem cells improve myocardial protection after ischemia or infarction. Proc. Natl Acad. Sci. USA 106(41), 17499-17504 (2009).

27 Ghanem A, Steingen C, Brenig F et al. Focused ultrasound-induced stimulation of microbubbles augments site-targeted engraftment of mesenchymal stem cells after acute myocardial infarction. J. Mol. Cell. Cardiol. 47(3), 411-418 (2009).

28 Ryzhov S, Solenkova NV, Goldstein AE et al. Adenosine receptor-mediated adhesion of endothelial progenitors to cardiac microvascular endothelial cells. Circ. Res. 102(3), 356-363 (2008).
29 Shen J, DiCorleto PE. Adenosine prompts the heart to recruit endothelial progenitors. Circ. Res. 102(3), 280-282 (2008).

30 Perin EC, Silva GV, Assad JA et al. Comparison of intracoronary and transendocardial delivery of allogeneic mesenchymal cells in a canine model of acute myocardial infarction. J. Mol. Cell. Cardiol. 44(3), 486-495 (2008).

31 Gilson WD, Kraitchman DL. Noninvasive cardiovascular imaging techniques for basic science research: application to cellular therapeutics. Rev. Esp. Cardiol. 62(8), 918-927 (2009).

32 Shi E, Kazui T, Jiang X et al. Therapeutic benefit of intrathecal injection of marrow stromal cells on ischemia-injured spinal cord. Ann. Thorac. Surg. 83, 1484-1490 (2007).

33 Bakshi A, Barshinger AL, Swanger SA et al. Lumbar puncture delivery of bone marrow stromal cells in spinal cord contusion: a novel method for minimally invasive cell transplantation. J. Neurotrauma 23, 55-65 (2006).

34 Riley J, Federici T, Park J et al. Cervical spinal cord therapeutics delivery: preclinical safety validation of a stabilized microinjection platform. Neurosurgery 65(4), 754-761; discussion 761-762 (2009).

\section{- Website}

101 Geron: GRNOPC1 www.geron.com/investors/factsheet/ pressview. $\cdot$ spx $? \mathrm{id}=1195$

\section{- Patent}

201 Marsala M. WO2008137760 (2008). 